University of Warwick institutional repository: http://go.warwick.ac.uk/wrap This paper is made available online in accordance with publisher policies. Please scroll down to view the document itself. Please refer to the repository record for this item and our policy information available from the repository home page for further information.

To see the final version of this paper please visit the publisher's website. Access to the published version may require a subscription.

Author(s): Jacqueline Sánchez Taylor

Article Title: Dollars Are a Girl's Best Friend? Female Tourists' Sexual Behaviour in the Caribbean

Year of publication: 2001

Link to published version:

http://dx.doi.org/10.1017/S0038038501000384

Publisher statement: None 


\title{
Dollars Are a Girl's Best Friend? Female Tourists' Sexual Behaviour in the Caribbean
}

\author{
Jacqueline Sánchez Taylor \\ Department of Sociology \\ University of Warwick
}

\begin{abstract}
Though increasingly a focus of both political concern and academic research, 'sex tourism' is a difficult term to define. This article presents both quantitative and qualitative data on the sexual behaviour and attitudes of single and/or unaccompanied heterosexual female tourists in the Dominican Republic and Jamaica. In so doing it aims to contribute to the body of research evidence on the phenomenon, as well as to highlight some of the conceptual problems associated with existing analyses of both 'sex tourism' and 'romance tourism'. It calls for the development of a theoretical model of sex tourism which can accommodate both the diversity of tourist-related sexual-economic exchanges which take place in economically underdeveloped countries and the complexity of the power relations that underpin them.
\end{abstract}

KEYWORDS gender, prostitution, race, sex tourism, sexual behaviour, tourism

Though increasingly a focus of both political concern and academic research, 'sex tourism' is a difficult term to define. The stereotypical image of the 'sex tourist' is that of the Western man who travels to Thailand or the Philippines in order to pay for sex with Go Go bar/brothel prostitutes. There is also a tendency amongst radical feminist writers to treat 'sex tourism' as though it simply involves men travelling abroad to engage in brief, highly commodified exchanges of sex for cash or kind with prostitute women or children. Enloe (1989:36), for instance, defines sex tourism as travel 'specifically to purchase the sexual services of local women', while Jeffreys (1998) holds that 'sex tourism' is more accurately termed 'prostitution tourism' and argues (p.70) that:

Prostitution tourism depends upon pro-prostitution abuse attitudes formed in the abusers' country of origin. Affluent cultures in the west and in the east which teach boys and men that the sexual use of women and children, irrespective of their pleasure or personhood, is a natural right of their masculinity, produce sex tourists and prostitution abusers.

These commentators treat sex tourism and prostitution as first and foremost an expression of male patriarchal power and female powerlessness, and their analyses do not therefore allow for the possibility of female sex tourism. Prostitute-users are, 
by definition, male, and this assumption is shared by many researchers and theorists who would not regard themselves or be regarded as 'radical feminists'. The sexual behaviour of female tourists in economically underdeveloped countries thus presents them with a conceptual dilemma. On the one hand, researchers often acknowledge that sexual relationships between local men and tourist women are based on an exchange of money or goods and gifts, but on the other they argue that the actors' narratives of romance and courtship make the term 'prostitution' inappropriate. The dilemma is captured in the following quote from Dahles and Bras, who conducted research on female tourists' sexual encounters with local men in Indonesia: 'prostitution is not the right concept to characterise these relationships, love is not the right concept either' (1999:287).

The behaviour of 'First World' women who travel to poor countries for sex with local men is generally interpreted in a very different way from that of 'First World' men who engage in the same practices. The tourist woman who buys meals and gifts for her local sexual partner is enjoying a 'romance', not using a prostitute. In academic studies as well as journalistic accounts, traditional notions of essential gender identity often inform an interpretation of the tourist women as passive innocents, 'used' by local men who are actively seeking money, a ticket off the island and maybe love, as well as sexual experience. Thus they have been sympathetically described as 'lonely women' whose 'economic and social ability to travel alone is being exploited by Caribbean tourism' and by the 'beach boys' who offer the possibility either of a 'holiday romance' or 'sexual harassment' (Momsen 1994:116). Indeed, few studies refer to the phenomenon of 'female sex tourism', but prefer instead the term 'romance tourism' (Dahles and Bras 1999; Momsen 1994; Pruitt and LaFont 1995; Meisch 1995). Some even suggest that 'romance tourism' has positive features, in that it supposedly provides a space for challenging traditional gender roles:

Whereas sex tourism serves to perpetuate gender roles and reinforce power relations of male dominance and female subordination, romance tourism in Jamaica provides an arena for change. By drawing on their respective traditional gender models as well as their imaginings and idealisations of each other and new possibilities the partners in these relationships explore new avenues for negotiating femaleness and maleness.

[Pruitt and LaFont 1995:423]

Definitional problems are compounded by the fact that there is very little empirical evidence on the sexual behaviour of tourist women. While a growing recognition of the links between Human Immuno-deficiency Virus (HIV) transmission and population mobility has prompted a good deal of quantitative research on sexual activity in the context of holidays and travel abroad (Clift and Forrest 1999; Bloor et al. 1998; Kleiber and Wilke 1995 cited in Oppermann 1998), there have been no large-scale studies to date which focus exclusively on tourist women's sexual behaviour. Equally, the phenomenon of women travelling for sex has attracted far 
less research attention than has male sex tourism (Albuquerque 1999). This article presents both quantitative and qualitative data on the sexual behaviour and attitudes of single and/or unaccompanied heterosexual female tourists in the Dominican Republic and Jamaica. In so doing it aims to contribute to the body of research evidence on the phenomenon, as well as to highlight some of the conceptual problems associated with existing analyses of both 'sex tourism' and 'romance tourism'. It calls for the development of a theoretical model of sex tourism which can accommodate both the diversity of tourist-related sexual-economic exchanges which take place in economically underdeveloped countries and the complexity of the power relations that underpin them.

\section{Background to the research}

The survey reported below was conducted as part of a larger Economic and Social Research Council (ESRC) funded research project on sex tourism in the Dominican Republic and Jamaica. ${ }^{1}$ This research employed a range of ethnographic methods to gather data on the lived experience of local people who are involved in tourist-related prostitution, as well as that of expatriates who organise and promote sex tourism. One of its aims was to examine the divergent experiences of male and female sex workers in relation to various macro-level features, such as legal and institutional factors, popular discourses on gender, 'race', and sexuality, and so on, and in relation to different patterns of demand from male and female tourists. Given the general lack of empirical evidence on the sexual behaviour of female tourists, it seemed appropriate to try to supplement our more detailed qualitative research with a relatively small sample of female tourists and local men who enter into sexualeconomic exchanges with tourists by administering a short questionnaire to a larger sample of women.

A questionnaire was constructed which was designed to yield some basic data on tourist women who had sexual contact with local men, including their nationality, age, occupation and racialised identity; their perceptions of the 'sexual culture' of the host country; how often they had travelled to that country and other known sex tourist destinations; how many different local sexual partners they had and whether they perceived these relationships as 'real love', 'holiday romances' or 'purely physical'; whether or not they gave money or made other gifts to their local sexual partners; whether or not they took safer-sex precautions. The idea was that data from in-depth interviews could then be triangulated against this information, so that we would have some way of assessing its validity and the representativeness of our sample of interviewees. However, preliminary analysis of the survey data suggests that it is also of interest in its own right.

Questionnaires were administered to 240 female tourists in three tourist resorts: Negril in Jamaica and Boca Chica and Sosua in the Dominican Republic. All tourist 
women who were on a given section of the beach at the time of survey were approached, and those who spoke English and were single or travelling without their partner/spouse were asked to complete a self-administered questionnaire for a study on tourism and sexual health. They were also told that the questionnaire contained questions on sensitive topics, and assured of anonymity and confidentiality. For further reassurance, envelopes were provided for finished questionnaires (see Wellings et al. 1994). Questionnaires took on average between ten to fifteen minutes to complete and included a mixture of multiple-choice questions and open-ended attitudinal questions.

This process was repeated at different times of the day and on different sections of the beach in order to obtain the widest possible sample of tourist women. Respondents were usually sunbathing, alone or with friends, relaxed and largely unoccupied and refusal to participate on grounds other than language was minimal. There were only fifteen refusals in all. The very high response rate (92.5 per cent) was perhaps due in part to women's familiarity with questionnaires on sexual behaviour and health in women's magazines such as Cosmopolitan. Many respondents expressed curiosity and concern for the topic under investigation, which may also explain their willingness to take part.

\section{Survey findings}

Preliminary analysis reveals that almost a third of the sample (seventy-five women) had engaged in one or more sexual relationships with local men during the course of their holiday. Set against data from surveys on tourists taking holidays in Europe, this finding suggests that single or unaccompanied female tourists to the Caribbean are much more likely to have sex with new sexual partners whilst on holiday (see Clift and Forrest 1999:282). The women who had entered into sexual relationships with local men were not a homogenous group in terms of background characteristics. They ranged in age from girls in their late teens to women in their 60 , though women in the 30-40 age group were the most likely to have had sex with local men Although only English-speaking women were able to complete the questionnaire, the sample included a cross section of tourists from Europe and North America. Set against statistics from the Economic Intelligence Unit (EIU 1998a and 1998b) on tourist arrivals for the two countries, the sample appears to be reasonably representative in terms of the nationality of tourists. ${ }^{2}$ In terms of racialised identities, respondents who had entered into sexual relationships with local men more or less mirrored the composition of the sample as a whole, which is to say the vast majority were white. ${ }^{3}$

The survey findings suggest that there may be a connection between sexual behaviour and the number of visits made to a given destination. In Jamaica, only 11 per cent of those who admitted to having a local sexual partner were on their first 
Table 1

Female Tourists Who Did and Did Not Enter into Sexual Relationships with Local Men by Number of Visits to Jamaica or the Dominican Republic

\begin{tabular}{|c|c|c|c|c|}
\hline $\begin{array}{l}\text { Number of previous visits } \\
\text { made to the country }\end{array}$ & $\begin{array}{c}\text { Female tourists } \\
\text { in Jamaica } \\
\text { who had sex } \\
\text { with local men } \\
\%\end{array}$ & $\begin{array}{c}\text { Female tourists } \\
\text { in Jamaica who } \\
\text { had not had sex } \\
\text { with local men } \\
\%\end{array}$ & $\begin{array}{c}\text { Female tourists } \\
\text { in the } \\
\text { Dominican } \\
\text { Republic } \\
\text { who had sex } \\
\text { with localmen } \\
\%\end{array}$ & $\begin{array}{c}\text { Female tourists } \\
\text { in the } \\
\text { Dominican } \\
\text { Republic who } \\
\text { had not had sex } \\
\text { with local men } \\
\%\end{array}$ \\
\hline On first visit & 11 & 68 & 30 & 58 \\
\hline 2-4 previous visits & 32 & 20 & 13 & 19 \\
\hline 5 or more previous visits & 36 & 11 & 13 & 9 \\
\hline No response to these questions & 19 & 1 & 43 & 13 \\
\hline$n$ & 52 & 105 & 23 & 53 \\
\hline
\end{tabular}

visit to the country. Some 32 per cent had visited Jamaica between two and four times, 36 per cent had visited more than five times. Of those women who had not had sexual relationships with local men, almost the reverse was true: 68 per cent of them were visiting for the first time, while just over 30 per cent had previously taken holidays in Jamaica. In the Dominican Republic, there were many more first-time visitors in the sample of those who had entered into sexual relationships with local men (which may reflect the fact that the Dominican Republic has only recently started to attract large numbers of tourists from English-speaking countries), but 26 per cent of the women who had entered into sexual relationships with local men were nonetheless on return visits to the country (see Table 1). However, it should be noted that there was a very high non-response rate amoung the Dominican sample to this question.

The majority of the women who had entered into sexual relationships whilst on holiday stated that they had formed only one such relationship. Most of these were either first-time visitors to the country or repeat visitors continuing a former 'friendship' established on a previous holiday. However, 27 per cent of women in both countries reported entering into sexual relationships with two or more partners (Table 2). These women were virtually all on return visits to the country, and would appear to fit with Albuquerque's (1999) category of 'veteran female sex tourists', that is, women who make repeated visits to a given country in pursuit of sex with multiples of local partners.

\section{Respondents' perceptions of relationships with local men}

Respondents who reported that they had entered into sexual relationships 
Table 2

Female Tourists Who Enter into Sexual Relationships with Local Men by Number of Local Sexual Partners

\begin{tabular}{lccc}
\hline $\begin{array}{l}\text { Number of local sexual partners } \\
\text { in the course of holiday }\end{array}$ & $\begin{array}{c}\text { Jamaica } \\
\%\end{array}$ & $\begin{array}{c}\text { Dominican Republic } \\
\%\end{array}$ & $\begin{array}{c}\text { Total } \\
\%\end{array}$ \\
\hline 1 & 67 & 65 & 66 \\
$2-5$ & 25 & 30 & 27 \\
More than 5 & 4 & 0 & 3 \\
No response & 4 & 4 & 4 \\
$n$ & 52 & 23 & 75 \\
\hline
\end{tabular}

with a local man or men in the course of their stay were asked whether they had ever been approached by a prostitute, 'gigolo' or 'sanky panky' (terms used in Jamaica and the Dominican Republic respectively to refer to male prostitutes). About a quarter answered that, yes, they had been offered sex on a commercial basis, but not a single respondent in either country admitted to having ever taken up the offer. Clearly, these women did not perceive their sexual encounters with local men as prostituteclient transactions or view their sexual partners as prostitutes/gigolos. This is interesting given that almost 60 per cent did acknowledge an economic element to their relationships (see Table 3). They were asked whether they had ever 'helped' their local boyfriend(s) out by giving cash, gifts or by buying them meals. In Jamaica, 38 per cent of the tourists who had entered in sexual relationships with local men said that they had given their boyfriends cash, 33 per cent had helped with gifts and 54 per cent had bought meals. Only 35 per cent stated that they had never 'helped' their boyfriend out in any way. In the Dominican Republic, women were rather less likely to acknowledge economic support provided to local boyfriends -26 per cent said they had helped with meals, 9 per cent with gifts and 13 per cent admitted to giving cash.

Table 3

Female Tourists Reporting 'Helping Out' their Local Sexual Partner(s)

\begin{tabular}{lccc}
\hline & $\begin{array}{c}\text { Female } \\
\text { tourists in } \\
\text { Jamaica } \\
\%\end{array}$ & $\begin{array}{c}\text { Female } \\
\text { touristsin the } \\
\text { Dominican Republic } \\
\%\end{array}$ & $\begin{array}{c}\text { Female } \\
\text { tourists in } \\
\text { both countries } \\
\%\end{array}$ \\
\hline Gave help in form of cash, gifts & & & \\
$\quad$ and/or meals & 65 & 39 & 57 \\
Never'helped' local partner(s) & 35 & 52 & 40 \\
No response & 0 & 9 & 3 \\
$n$ & 52 & 23 & 75 \\
\hline
\end{tabular}


Table 4

Female Tourists' Descriptions of Their Sexual Relationships with Local Men

\begin{tabular}{lccc}
\hline & Jamaica & $\begin{array}{c}\text { Dominican } \\
\text { Republic }\end{array}$ & $\begin{array}{c}\text { Both } \\
\text { countries } \\
\text { Description of relationship }\end{array}$ \\
\hline Holiday romance & $\%$ & $\%$ & $\%$ \\
Real love & 42 & 26 & 39 \\
Purely physical & 13 & 39 & 22 \\
Both physical and holiday romance & 4 & 9 & 3 \\
Long-term & 13 & 4 & 5 \\
Several types & 6 & 4 & 8 \\
Other & 10 & 9 & 8 \\
No response & 10 & 4 & 3 \\
$n$ & 2 & 23 & 75 \\
\hline
\end{tabular}

Respondents were also asked whether they would describe their relationships with local men as 'true love', 'holiday romance' or 'purely physical'. In Jamaica, women who had sexual relationships with local men were more likely to describe these relationships as 'holiday romance' ( 42 per cent) than 'real love' (13 per cent), whereas in the Dominican Republic, they were more likely to describe their relationships as 'real love' (39 per cent) than as 'holiday romance' ( 26 per cent). Only 3 per cent of the whole sample that had entered into sexual relationships with local men described their sexual encounters as 'purely physical', with a further 12 per cent stating that their relationships were both 'purely physical' and 'holiday romance' (Table 4). Those who described their relationships as 'holiday romances' used the term in a fairly flexible way. It covered a broad spectrum of sexual encounters, everything from a one night stand to relationships that lasted a week or a month. One woman stated that she had three 'holiday romances' in the space of a week, for example.

\section{Safer sex practices}

Of the seventy-five tourist women who reported entering into sexual relationships with local men in Jamaica or the Dominican Republic, 81 per cent stated that they took some form of precaution against sexually transmitted diseases (STD's); however only 67 per cent reported using condoms and 15 per cent stated that they took no precaution whatsoever against the risk of STDs (and it is interesting to note that these were women who described their relationships with local men as 'real love'). Some respondents even confused contraceptive protection with protection against STDs. Those who stated that they used condoms were asked who supplied them. The majority replied that both partners supplied condoms, with 16 per cent 
stating that only they themselves provided condoms. These findings may compare unfavourably with similar research on gay males' safer-sex practice (see, for instance, Clift and Forrest 1999), but they are consistent with research that has found an extremely high level of unprotected sex between heterosexual tourists in European holiday destinations. Research on single heterosexual tourists who have sex whilst on holidays in Europe (mostly with each other, rather than with local people) suggests that between 25 per cent (Bloor et al. 1997, cited in Clift and Forrest 1999) and 71 per cent (Conway et al. 1990, cited in Clift and Forrest 1999) do not consistently use a condom. These studies, like other work in this area, further suggest that women are less likely to use condoms with new partners than men and are more likely to engage in unprotected sex than men as they often experience problems getting their male partners to use condoms (Mulhall 1996; Rosenthal et al.1998). Indeed, it has been convincingly argued that women's inability to enforce the use of condoms is a measure of their relative powerlessness in heterosexual sexual encounters (Thomas 2000; Holland et al.1991, 1998). Bloor et al. (1998), found that women's risk behaviour abroad is often inconsistent with their behaviour at home and more likely to be shaped by the 'characteristics of their sexual partner'. In the light of such research, the fact that 68 per cent of female tourists who had sex with Jamaican and Dominican men reported condom use suggests that the women enjoyed a relatively high level of control within their sexual encounters with local men, and it is equally important to note that those women who had multiple sexual partners and/or who acknowledged 'helping' their partner(s) out financially in some way were also those most likely to use condoms.

\section{'Sex tourism' or 'romance tourism'?}

The survey reported above found that almost one third of a sample of 240 single or unaccompanied female tourists in the Caribbean entered into sexual relationships with a local man or men. This finding is, perhaps, useful in relation to the more general literature on travel and sexual behaviour, but it does not, on its own, help to resolve questions about gender and sex tourism. Can their behaviour be interpreted in the same way as that of male tourists who enter into sexual relationships with local women? In her 1997 book Gender and Nation, Yuval-Davis briefly comments on the globalisation of sexual exploitation. In the paragraph on male sex tourism, she refers to 'male orientalist dreams of inexhaustible pools of sexual pleasures and "exotic" sexual objects', and in relation to 'Mail-order brides', she speaks of the 'incredible hardship' from which women who enter into such marriages seek to escape (1997:52). The next paragraph deals with female tourists' sexual behaviour and paints a very different picture (p.52):

The 'Shirley Valentine' phenomenon where women are the tourists is somewhat similar to that of men, although here formal prostitution, in the form of male gigoloism, is less 
common than just consenting casual or not so casual sex. The exchange here is more on the basis of mutual pleasure than on money for pleasure. The western women tourists are in search of sexual adventures and experimentation while away from home, and the local men get free sex not available to them from the local women who are under strict social control.

It is true that tourist women in Jamaica and the Dominican Republic do sometimes enter into sexual relationships with middle-class local men who are their economic equals or even superiors, and such relationships may conform to the description provided by Yuval-Davis. But this is the exception rather than the rule. The Dominican Republic and Jamaica are poor countries, heavily indebted to international financial institutions. It is estimated that 44 per cent of Dominicans and around one third of Jamaicans live below the poverty line (EIU 1998a; Mullings 1999). On the whole, tourist women spend their time on the beach, in their hotels and in tourist bars and nightclubs. The local men they meet and enter into sexual relationships with are usually working-class, either hotel or bar workers, or 'beach boys', i.e., young men who stuggle to make a living by engaging in various forms of 'hustling. This may include any one or a combination of the following activities: promotion for restaurants, clubs and watersports businesses, acting as tour guides, selling drugs, procuring female prostitutes for male tourists, life guard, providing boat tours or snorkelling instruction. Most beach boys enter into sexual relationships with as many tourist women as they possibly can, and most of these relationships result in some form of material or economic benefit for the man. Some beach boys and hotel or bar workers engage in explicit sex for cash exchanges with male tourists, female tourists and/or tourist couples, but on the whole, the economic element of their sexual relationships with tourist women is less formally arranged.

The survey found that about 60 per cent of the women who had sex with local men acknowledged an economic element to their relationship(s). The latter figure is unlikely to accurately describe the true level of economic benefits transferred to local men by these women, however. First of all, there is likely to have been underreporting by tourist women, who may not interpret their own behaviour as 'helping out financially'. For example, one woman who filled in the questionnaire stating that she had not helped her boyfriend out financially later noted that she was paying for a house to be built on his land. She described this as a 'business proposition' rather than a gift to her boyfriend. Moreover, in interviews beach boys observed that they often do not reap a financial reward from their relationships with female tourists until after the woman has returned home. Many European and American women send cash and gifts to their Jamaican or Dominican 'boyfriends', and several beach boys stated that they have enjoyed periods during which as many as five different women were sending them monthly remittances of between US\$20 and US $\$ 100$. Secondly, tourist women do not always realise how their local partners extract a financial benefit from them. Beach boys explained that the trick is to take women to 
bars, shops and restaurants where friends work, ensure that they are over-charged for goods, and then split the reward with the friend. Finally, many tourist women do not appreciate just how poor the men they have sex with are, and so do not understand that simply letting them have a hot shower in a hotel room, or paying for a snack or drinks can be construed as a material benefit.

The real point, however, is that a significant number of tourist women in Jamaica and the Dominican Republic enter into sexual relationships with local men that have at least some economic element to them. Few of them view these relationships as a form of prostitution, however, and nor are the relationships always viewed by the local men as such. In interviews, few beach boys openly self-identified as prostitutes, gigolos or sanky pankies. Many local men tap into traditional gendered 'mating' roles, using chat up lines and 'sweet talk' in order to construct a fantasy of courtship to pick up tourist women, and do not acknowledge that they are approaching tourist women specifically for some form of financial gain. Even when local men acknowledged that they secured material and financial benefits from entering into sexual relationships with a series of tourist women, and described strategies for selecting women who were most likely to be 'generous' as well as strategies for extracting cash benefits from their female sexual partners, they rarely saw themselves as 'prostitutes' or 'sex workers'.

Participants in these sexual relationships thus interpret their experience through highly gendered, commonsense understandings of both 'courtship' and 'prostitution' within which women cannot be sexually predatory but only preyed upon. Only women and homosexual men can be prostitutes, and only men can be prostitute-users. And it is because ethnographic researchers who have studied the phenomenon have been mainly concerned with the subjective meanings that participants attach to their sexual behaviour and relationships that they have found it so difficult to define or categorise relationships between tourist women and local men, and have ended up making a conceptual distinction male 'sex tourism' and female 'romance tourism' (Dahles and Bras 1999; Pruitt and LaFont 1995; Meisch 1995).

My own research suggests that this distinction is problematic for four main reasons. First of all, it reflects a misunderstanding of male sex tourism. It is true that some men travel in order to indulge in brief, straightforward cash for sex exchanges in brothels or other establishments. But male tourists also engage in a wide range of different types of sexual-economic relationships with local women, children and men. In the Caribbean and Latin America, as well as in South East Asian countries, a large informal sex industry operates around tourism which includes women, children and men working on a freelance basis from bars and beaches. In this informal sector, sexual-economic exchanges are not always organised as straightforward, narrowly focused prostitution contracts (see O'Connell Davidson 1995, 1998). For example, some women and children do not negotiate prices up front or 
place limits on the time spent with the tourist or the sexual acts they are willing to perform. Some do not even consider themselves to be prostitutes, as their primary motivation for entering into sexual relationships with tourists is the hope that it will lead to marriage and a passport out of the country. Many women are willing to act as tourists' 'girlfriends', to offer affection, to dance with them, hold their hands, rub their backs, wash their socks and so on, and do not ask for 'payment' but rather accept 'gifts' of clothing, meals and cash from their 'boyfriends'. Sexualised racisms are used by the men to tell themselves that sex is more 'natural' and that promiscuity is 'a way of life' in the countries they visit, and that the women and children they have sex with are not like the prostitutes back home, but are just 'doing what comes naturally' to them (Sánchez Taylor 2000).

This means that male tourists who enter into sexual relationships with local women and girls in the 'Third World' destinations they visit do not always or necessarily perceive themselves as prostitute-users or think of themselves as 'purchasing the sexual services of local women'. In a survey of 661 German male tourists who had sex with local women in the Dominican Republic, Kenya, and Thailand, Kleiber and Wilke (1995, cited in Oppermann 1998) found that only 20 per cent considered themselves to be 'sex tourists' even if they travelled with the specific intention of developing a sexual relationship with a local woman. Are these men 'romance tourists' because they do not subjectively view their own behaviour as a form of prostitute-use?

Secondly, it is important to recognise that women, as well as men, can be sexually hostile and predatory. Interview work with beach boys in the Dominican Republic and Jamaica, as well as with taxi drivers and other informants suggests that some women do actually take a narrowly instrumental and impersonal approach to sex with local men, and are quite willing to enter into explicitly commercial sexual relationships. This group of women are certainly in the minority, but are nevertheless present, and will specify their exact requirements as purchasers of sexually objectified bodies. They pay third parties to procure men or boys of a particular age, penis size, skin tone, body type and even smell, and negotiate prices up front. A third problem with the male sex tourism/ female romance tourism distinction is that it rests on and reproduces essentialist understandings of male and female sexuality. The local man is assumed to be necessarily getting some benefit beyond the economic simply because he is a man getting to have sex with a woman. Likewise, it is assumed that the female tourist must be being exploited in some way, simply because she is a woman giving a man sexual access to her body.

Finally, the idea that tourist women who have sex with local men are not really 'sex tourists' reflects a theoretical privileging of gendered power over questions of racism and racialised power, as well downplaying the significance of economic power. Interview work with female tourists show very clearly that notions of 'racial' otherness and difference play a key role in allowing women tourists, as much as their 
male counterparts, to ignore imbalances of age and economic power between themselves and their local sexual partners. Racist ideas about black men being hypersexual and unable to control their sexuality enabled them to explain to themselves why such young and desirable men would be eager for sex with older, and/or often overweight women, without having to think that their partners were interested in them only for economic reasons. The men in Jamaica and the Dominican Republic are not selling sex, but doing what comes naturally to them. Only women who had entered into a series of brief sexual encounters began to acknowledge that 'it's all about money'.

Like male sex tourists, being able to command 'fit' and sexually desirable bodies which would otherwise be denied to them reaffirms female tourists' sense of their own privilege as 'First World' citizens. The Caribbean is a space that is constructed as different. Sexual mores are different, people are naturally promiscuous and sex is more natural. A few of the women interviewed expressed overtly hostile racism towards local men. They wanted to transgress both the racialised and gendered codes that normally govern their sexual behaviour, while maintaining their honour and reputation back home. Most, however, tap into exoticising rather than denigrating racisms and use their economic power to control the relationship in ways in which they could never do with men back home. White women, in particular, explained that they felt valued in the Caribbean in ways in which they are not back home. Their economic power and their whiteness means that they are not treated as local women but respected and protected. Their bodies are also valued over local women's bodies and they are offered a stage upon which they can simultaneously affirm their femininity through their ability to command local men and reject the white men who have rejected them (see Sánchez Taylor 1997, 2000). Feminists who recognise that male sex tourism is fuelled by 'orientalist dreams of inexhaustible pools of sexual pleasures and "exotic" sexual objects', need also to question the motivations and fantasies of Western tourist women who search out 'sexual adventures and experimentation' with 'exotic' Other men (Yuval-Davis 1997:52).

\section{Conclusion}

This paper has emphasised similarities between the behaviour and attitudes of male and female tourists from affluent countries who enter into sexual relationships with local people in the economically underdeveloped countries they visit. I should also note that there are important respects in which patterns of sexual interaction between tourist women and local men differ from patterns of sexual interaction between tourist men and local women. There is a formally organised female prostitution sector in both Jamaica and the Dominican Republic, and tourist men make extensive use of this sector, especially in the Dominican Republic. Female street prostitution, within which women offer specific and limited sexual services in exchange for a set fee, also exists in both countries, and again, tourist men provide 
demand for these services. There is no equivalent commercial market of male prostitutes catering to the desires of female tourists. Tourist women are much less likely than their male counterparts to enter into narrow and explicit cash for sex exchanges with locals.

Nor should we forget that male tourists enjoy gendered, as well as economic and racialised power over local females, and that local women and girls working in both formally and informally organised tourist-related prostitution often report being cheated, beaten and raped by their tourist clients. Beach boys are not vulnerable to violence from their female tourist sexual partners in this way (Sánchez Taylor 1997). Neither are they vulnerable to police harassment and legal prosecution in the same way that local women who enter into sexual-economic exchanges with male tourists are, for prostitution law in both countries is designed to control female, not male, sexuality. Finally, I should note tourist women's privilege is at least partly contingent on their social, economic and political status. Those who migrate to live in Jamaica or the Dominican Republic on a permanent basis, rather than visiting temporarily as tourists, risk losing certain rights and freedoms. We interviewed a number of North American and European women who had migrated in order to marry or live with the local boyfriend they had made on holiday and were now in extremely abusive relationships. They state that when they have reported being raped, beaten or robbed by boyfriends or husbands to the police, no action is taken to protect them. As one woman said, 'the police just laugh in your face. If you live with the guy, you belong to him'. For women, white privilege can be jeopardised by entry into permanent or semi-permanent sexual relationships with black men, whereas white men's whiteness is never called into question by their sexual contact with black women.

Recognising these kinds of differences should not force us to discount similarities between male and female tourists' sexual experiences and privileges, however. It is important to work towards developing a theoretical framework that can accommodate the complex and contradictory interplay between gendered, raced and economic power in shaping the experience of both tourists and locals, for it is this complexity which has so often been overlooked in accounts of both male 'sex tourism' and female 'romance tourism'.

Empirical data on female tourists who enter into sexual-economic exchanges with local men highlights gaps and weaknesses in existing theoretical approaches to sex tourism. Focusing on gendered power can easily slip into accepting gender essentialist models of sexuality within which the sexual behaviour of women is interpreted and judged differently from that of men simply because they are women. Gender is not a unitary category undifferentiated by class or race, and the power relations involved in heterosexual encounters are therefore not always identical, even if discourses of heterosexual romance construct them as such. Sexual relationships between local men and tourist women are typically relationships between individuals who are massively unequal in terms of economic and political power, usually 
also unequal in terms of racialised power. Very often there is also a large age gap between the tourist woman and the local man. These inequalities exist whether or not the individuals concerned make sense of these relationships through reference to discourses of heterosexual 'romance'. Definitions of, and theoretical approaches to, sex tourism which fail to take such inequalities into account cannot hope to capture or explain the diversity and complexity of sexual-economic exchanges between tourists and locals.

\section{ACKNOWLEDGEMENTS}

The support of the Economic and Social Research Council which funded the research upon which this paper is based (award no. Roo0237625) is gratefully acknowledged. I am also indebted to Julia O'Connell Davidson, without whom this paper would never have been finished.

NOTES

1. This research was undertaken by the author and Julia O'Connell Davidson between 1998 and 2000.

2. In 1997,65 per cent of visitors to Jamaica were from the US, while Europeans accounted for 20 per cent of tourist arrivals (EIU, 1998b). In the Dominican Republic there has recently been a shift in the tourist market with arrivals from Europe increasing rapidly and overtaking those from the United States. Europeans are now estimated to account for 57 per cent of visitors, while 22.9 per cent of tourists come from the United States and 8.7 per cent from Canada. Although the Dominican Republic attracts large numbers of Germans and Spanish tourists, they are underrepresented in this sample because many did not speak English and the questionnaire could only be completed by those who are fairly fluent in English (however 23 per cent of respondents spoke English as a second language).

3. There is no background data on tourist arrivals to each country broken down in terms of racialised identities, so it is not possible to say whether respondents, 77 per cent of whom self-identified as white, 10 per cent as black and the rest as Asian or 'other', are representative of tourists to Jamaica and the Dominican Republic more generally. There was a marked difference between the samples drawn from the two countries, however. In Jamaica 15 per cent of those surveyed self-identified as black and 2 per cent as other and 1 per cent as Asian. In the Dominican Republic 2 per cent of the women self-identified as black. Overall, 35 per cent of white female tourists surveyed had entered into sexual relationships with local men, while only 16 per cent of the female tourists who identified as black, Asian or 'other' had done so. However, the sample of black tourists is far too small to base any generalisations upon.

\section{REFERENCES}

Albuquerque, K. 1999. 'Sex, Beach Boys and Female Tourists in the Caribbean', in B. M. Dank and R. Refinetti (eds.), Sex Work and Sex Workers: Sexuality and Culture, Vol. 2. New Jersey: New Brunswick.

Bloor, M., Thomas, M., Hood, K., Abeni, D., Boujou, C., Hausser, D., Hubert, M., Dieter, K. and Nieto, J.A. 1997. 'Feasibility Study for Co-operated Community Action on the Improved Targeting of HIV/AIDS Campaigns Amoung International Travellers: Final Report'. Cardiff: School of Social and Administrative Stuides, Cardiff University of Wales (unpublished). 
Bloor, M., Thomas, M., Hood, K., Abeni, D., Boujou, C., Hausser, D., Hubert, M., Dieter, K. and Nieto, J. A. 1998. 'Differences in Sexual Risk Behaviour between Young Men and Women Travelling Abroad from the UK'. The Lancet 352:1664-8.

Clift, S. and Forrest, S. 1999. 'Factors Associated with Gay Men's Sexual Behaviour and Risk on Holiday'. AIDS Care 11:281-95.

Conway, S., Gillies, P. and Slack, R. 1990, 'The Health of Travellers'. Nottingham: Department of Public Health Medicine and Epidemiology, University of Nottingham and Nottingham Health Authority (unpublished).

Dahles, H. and Bras, B. 1999. 'Entrepreneurs in Romance: Tourism in Indonesia'. Annals of Tourism Research 26:267-93.

Economic Intelligence Unit (EIU) 1998a. County Profile: Dominican Republic, Haiti, Puerto Rico 1998-1999. London: Economic Intelligence Unit.

Economic Intelligence Unit (EIU) 1998b. Country Profile: Jamaica, Third Quarter of 1998. London: Economic Intelligence Unit.

Enloe, C. 1989. Bananas, Beaches and Bases: Making Feminist Sense of International Politics. London: Pandora.

Holland, J., Ramazanoglu, C., Scott, S., Sharpe, S. and Thomson, R. 1991. 'Between Embarrassment and Trust: Young Women and the Diversity of Condom Use', in P. Aggleton, P. Davies and G. Hart (eds.), AIDS: Responses, Interventions and Care. London: Falmer Press.

Holland, J., Ramazanoglu, C., Scott, S., Sharpe, S. and Thomson, R. 1998. The Male in the Head. London: Tufnell Press.

Jeffreys, S. 1998. 'Child Versus Adult Prostitution: A False Distinction, pp. 65-71 in S. Jeffreys (ed.), Fight Against Child Sex Tourism: Participants' Speeches and Contributions. Brussels: European Commission.

Kleiber, D. and Wilke, M. 1995. Aids, Sex und Tourismus: Ergebnisse einer Befragung deutscher Urlauber und Sextouristen. Baden-Baden: Nosmos-Verlagsgesellschaft.

Meisch, L. 1995. 'Gringas and Otavalenos: Changing Tourists Relations'. Annals of Tourism Research 22:441-62.

Momsen, J. 1994. 'Tourism, Gender and Development in the Caribbean', in V. Kinnaird and D. Hall. (eds.), Tourism: A Gender Analysis. Chichester: Wiley.

Mulhall, B. P .1996. 'Sex and Travel: Studies of Sexual Behaviour, Disease and Health Promotion in International Travellers - A Global View'. International Journal of STD and AIDS 7:455-65.

Mullings, B. 1999. 'Globalization, Tourism and the International Sex Trade', in K. Kempadoo (ed.), Sun, Sex, Gold: Tourism and Sex Work in the Caribbean. Oxford: Rowman and Littlefield.

O'Connell Davidson, J. 1995. 'British Sex Tourists in Thailand', in M. Maynard and J. Purvis (eds.), (Hetero)sexual Politics. London: Taylor \& Francis.

O'Connell Davidson, J. 1998. Prostitution, Power and Freedom. Cambridge: Polity.

Opperman, M. 1999. 'Introduction', in M. Opperman (ed.), Sex Tourism and Prostitution: Aspects of Leisure, Recreation and Work, New York: Cognizant Communication Corporation.

Pruitt, D. and LaFont, S. 1995. 'For Love and Money: Romance Tourism in Jamaica'. Annals of Tourism Research 22:422-40.

Rosenthal, D., Gifford, S. and Moores, S. 1998. 'Safe Sex or Safe Love: Competing Discourses'. Aids Care 10:35-47.

Sánchez Taylor, J. 1997. 'Marking the Margins: Research in the Informal Economy in Cuba and the Dominican Republic'. Discussion Papers in Sociology, No. S97/1.

Sánchez Taylor, J. 200o. 'Tourism and “Embodied" Commodities: Sex Tourism in the Caribbean', in S. Clift and S. Carter (eds.), Tourism and Sex: Culture, Commerce and Coercion. London: Pinter. Thomas, M. 2000.'Exploring the Contexts and Meaning of Women's Experience of Sexual 
Intercourse on Holiday', in S. Clift and S. Carter, (eds.), Tourism and Sex: Culture, Commerce and Coercion. London: Pinter.

Wellings, K., Field, J., Johnson, A., Wadworth, J. with Bradshaw, S. 1994. Sexual Behaviour in Britain: The National Survey of Sexual Attitudes and Lifestyles. London: Penguin Books.

Yuval-Davis, N. 1997. Gender and Nation. London: Sage.

Biographical note: JACQUELINE SÁNCHEZ TAYLOR has undertaken extensive research on sex tourism in the Caribbean, Latin America, South Africa and India which was commissioned by ECPAT (End Child Prostitution in Asian Tourism). She has recently come to the end of an ESRC project on tourist-related prostitution in the Caribbean and has a particular research interest in the phenomenon of female sex tourism and the racialised, gendered and sexualised discourses that tourist women and local men use to organise, explain and justify their sexual interactions.

Address: Department of Sociology, University of Warwick, Coventry, CV47AL. 